\title{
A Three-year Retrospective Study of Perioperative Mortality at a Tertiary Children Hospital in Iran
}

mohammad gharavifard

Mashhad University of Medical Sciences

majid sharifian ( $\nabla$ sharifian.majid@yahoo.com )

Mashhad University of Medical Sciences

Research

Keywords: Mortality, Pediatric, Perioperative, Surgery

Posted Date: July 28th, 2020

DOI: https://doi.org/10.21203/rs.3.rs-48560/v1

License: (9) (1) This work is licensed under a Creative Commons Attribution 4.0 International License. Read Full License 


\section{Abstract}

Introduction: Mortality is a key criterion for quality and safety in surgery. Studies show the higher rate of perioperative mortality in children compared with adults. The aim of present study was to determine the mortality rate after surgery among pediatric population.

Methods: This retrospective study of perioperative mortality rate was performed in children younger than 18 years who operated at surgery unit of Dr. Sheikh pediatric tertiary hospital, Iran. Records of all cases of pediatric surgery performed under anesthesia between March 2015 and March 2018 were reviewed. Mortality rate at different time intervals after surgery, demographic characteristics and comorbidities of patients, type and duration of surgery, the number of operations in each child, the time interval between surgery and death, and the emergency level of surgery were recorded. Chi-square test was used for analysis of results.

Results: Out of 5,5027 surgeries, 214 deaths were recorded, $78.6 \%$ of which occurred within one month after surgery. Mortality rate per 10,000 surgeries in the first year was about 49, which dropped to 10 in the third year. The mean value of mortality within 30 -day post-surgery was 27.44 per 10000 procedures. The highest mortality rate was observed in people under 3 years of age with $67.2 \%$ and in females with $52.8 \%$. Cardiac disease was at the top of comorbidities among dead patients. There was significant relationship between age and type of surgery with time interval between surgery and death.

Conclusion: Infant age group and type of surgery was the main predictor of perioperative mortality.

\section{Introduction}

In recent years, the proportion of organizations that monitor the performance of medical and surgical procedures has increased significantly compared to all organizations act in the field of health care services. Increasing attention to medical errors, safety of medical interventions, and quality of postoperative care have reduced the incidence of unfavorable events and deaths after medical and surgical procedures (1).

Health indicators reflect the level of health in the society and the mortality rate of children is one of the most important health, cultural and economic indicators of any society that is considered in assessing the health of the society. Child mortality is so significant that one of the Millennium Development Goals was defined as the reduction in less than 5-year child mortality by less than two-thirds between 1990 and 2015. The reason for choosing this index as a development index is the effect of various social and economic factors in reducing or increasing it. Nearly 11 million children worldwide die each year before the age of five, and these deaths occur mainly in low-income and middle-income countries, especially in the deserts of Africa and South Asia (2).

Surgery is one of the most common treatments in many hospitals and also one of the most stressful events that can happen in a child's life. Surgery can be scheduled or unplanned, small or large, invasive or 
non-invasive, and involves any part or system of the body (3). Access to surgical care has been classified as one of the eight most important interventions to improve welfare of poor people in the world. $30 \%$ of the total diseases that lead to disability and death in the world could be treated with surgery. There is a high gap between the population of children and the number of physicians in the world. Efforts to reduce infant and child mortality rates have not paid much attention to children's surgical needs; therefore, the difference between the population of children and the population of surgical providers trained in child care is even greater (4). American College of Surgeons National Surgical Quality Improvement ProgramPediatric (NSQIP-Pediatric) dataset has determined the approximate value of the 30-day perioperative mortality as $0.3 \%$. With more than 5 million surgeries performed annually in the United States on children and infants, even a low mortality rate indicates that thousands of children are at risk of post-surgery death each year (5).

Mortality is an objective and key indicator for assessing the quality and safety of surgery (6). Perioperative mortality refers to death before discharge in patients who have undergone a surgical procedure especially within 30 days of surgery $(7,8)$. Studies show a higher rate of perioperative mortality in children compared with adults, which is also higher in neonates and infants among children of various ages (6). Assessing the rate and pattern of postoperative mortality can help surgeons and anesthesiologists to identify children who are at greater risk to prevent the death of these children or other serious injuries by better planning, proper distribution of resources and right use of specialists $(9,10)$.

Since no study done in Iran to determine child mortality after surgery, this study was conducted to determine the incidence of mortality especially within 30-day post-surgery in children.

\section{Materials And Methods}

This study was performed retrospectively using data from the electronic and archived medical records of patients operated on at Dr. Sheikh Children's Hospital, a tertiary university reference center, in Iran. The data were for three years from March 2015 to March 2018. Patients who were admitted to the surgery ward but did not undergo surgery were excluded from the study. Children who died within the hospital were categorized in to four groups according to mortality time after surgery including within 30 days, during 1 to 6 months, during 6 to 12 months, and after 12 months of procedure. Mortality cases were categorized into five groups according to age: neonates and infants up to 12 months of age, children at 1 to 3 years of age, children aged 3 to 6 years, children from 6 to 10 years of age and older children aged 10-18 year. The main outcome of study was perioperative mortality rate of children at various years, following by deaths occurred within 30 days of surgical procedure. However, characteristics of patients, type and duration of operation, number of procedure per patient, comorbidities, and emergency status of the surgery were also recorded. Mortality rate was expressed per 10000 procedures. To describe other data, descriptive statistics including percentage, frequency, and mean were used. Ethical committee of Mashhad University of medical sciences has approved the study. The study protocol need no informed consent, as patients were not the subject of any kind of actions but patient confidentiality on personal data protection was fully considered. 


\section{Results}

During the 3-year study period, 55,027 cases of surgery were recorded. Regardless of the time interval between surgery and death, and with respect to the all cases of death, the mean value of mortality incidence was 34.35 per 10000 surgeries. Table 1 shows the number of surgeries and mortality rates over the years. Perioperative mortality mean within 30 days was 27.44 per 10000 procedures. Table 2 demonstrates mortality rates according to various factors. It shows that on average, $78.6 \%$ of deaths occurred during the first 30 days after surgery, $15.6 \%$ of deaths were between 1 and 6 months after surgery, and $5.7 \%$ of deaths occurred in time intervals higher than six months after surgery. The highest rate of mortality (34.4\%) observed in infants younger than 1 year. Children 1 to 3 years old also exhibited nearly the same percent of deaths (32.8\%) as infants. Averagely, $52.8 \%$ of deaths were belonged to the females, however, studying the years separately showed that the mortality rate for boys in the first year of study was higher. Most patients (78.4\%) underwent surgery only once. The results showed that in the first year of the study, $8.2 \%$ of patients who died had undergone surgery three times, which was $2.5 \%$ in the second year and $0 \%$ in the third year. $35.8 \%$ of the dead patients had no comorbidities. The most common form of comorbidity among dead patients was cardiac disease with $18.9 \%$. Table 3 shows type and emergency status of surgery. Accordingly, $22.7 \%$ of the deaths were related to ostomy surgery, while $17.9 \%$ of mortalities were associated with peritoneal dialysis (PD) catheter implantation. Laparotomy, hernia and esophageal surgeries were other types of surgeries with most frequent death rate, respectively. Over time, the number of deaths from ostomy surgery increased dramatically, from $19.2 \%$ in the first year to $25.3 \%$ in the second year and $41.2 \%$ in the third year. The results showed that $73.7 \%$ of the surgeries that resulted in death were not at emergency status. The minimum, maximum, mean and standard deviations of the duration of surgery were $20,300,78$ and 48.78 minutes, respectively.

In order to investigate the relationship between age, sex, emergency status of surgery, and type of surgery with the time interval between surgery and death, the Chi Square test was used at a significant level of 0.05. The analysis of the association between age and time interval between surgery and death showed a $p$-value of 0.000 which indicates a significant relationship. The $p$-value of the relationship between sex with time interval between surgery and death was achieved 0.087 that was not significant. According to the $p$-value of 0.859 there was not ant significant relationship between emergency status of the surgery and time interval between surgeries to death. The p-value of the relationship between type of surgery and time interval between surgery and death was 0.013 which indicates a significant association.

Table 1

Comparison of perioperative mortality rates between different years

\begin{tabular}{|llll|}
\hline Years of study & Total N of surgeries & N of Deaths & Mortality rate per 10000 surgery \\
\hline $2015-2016$ & 20452 & 100 & 48.89 \\
\hline $2016-2017$ & 17920 & 79 & 44.08 \\
\hline $2017-2018$ & 16655 & 18 & 10.08 \\
\hline
\end{tabular}


Table 2

Perioperative mortality rates in 55027 surgeries according to demographic characteristics

\begin{tabular}{|c|c|c|c|}
\hline & & $\mathbf{N}$ & Valid\% \\
\hline \multirow[t]{5}{*}{ Age (year) } & $<1$ & 66 & 34.4 \\
\hline & $1-3$ & 63 & 32.8 \\
\hline & $3-6$ & 31 & 16.1 \\
\hline & $6-10$ & 18 & 9.4 \\
\hline & $>10$ & 14 & 7.3 \\
\hline \multirow[t]{2}{*}{ Sex } & Male & 58 & 47.2 \\
\hline & Female & 65 & 52.8 \\
\hline \multirow[t]{3}{*}{ surgeries per patient } & 1 & 152 & 78.4 \\
\hline & 2 & 32 & 16.5 \\
\hline & 3 & 10 & 5.2 \\
\hline \multirow[t]{10}{*}{ comorbidities } & non & 76 & 35.8 \\
\hline & Cardiac disease & 40 & 18.9 \\
\hline & Congenital Diseases & 10 & 4.7 \\
\hline & Malignancy & 13 & 6.1 \\
\hline & Obstruction GI & 20 & 9.4 \\
\hline & Bed sore & 1 & .5 \\
\hline & Obstruction Catheter & 5 & 2.4 \\
\hline & Hernia & 3 & 1.4 \\
\hline & Internal diseases & 42 & 19.8 \\
\hline & $\mathrm{CP}$ & 2 & .9 \\
\hline \multirow[t]{4}{*}{ Interval of surgery to death } & Less than 30 days later & 151 & 78.6 \\
\hline & between $1-6$ months & 30 & 15.6 \\
\hline & between 6-12 months & 5 & 2.6 \\
\hline & More than 12 months & 6 & 3.1 \\
\hline
\end{tabular}


Table 3

Perioperative mortality rates in 55027 surgeries according to type, and emergency status of surgery

\begin{tabular}{|llll|}
\hline \multirow{3}{*}{ Type of surgery } & & N & Valid \% \\
\cline { 2 - 4 } & Ostomy & 47 & 22.7 \\
\cline { 2 - 4 } & peritoneal dialysis (PD) catheter implantation & 37 & 17.9 \\
\cline { 2 - 4 } & Laparotomy & 30 & 14.5 \\
\cline { 2 - 4 } & hernia surgery & 23 & 11.1 \\
\cline { 2 - 4 } & Esophageal surgeries & 17 & 8.2 \\
\cline { 2 - 4 } & Antrectomy & 13 & 6.3 \\
\cline { 2 - 4 } & excision of tumor & 8 & 3.9 \\
\cline { 2 - 4 } & Other... & 32 & 15.4 \\
\hline & Yes & 56 & 26.3 \\
\cline { 2 - 4 } & No & 157 & 73.7 \\
\cline { 2 - 4 } & & & \\
\end{tabular}

\section{Discussion}

This study was the first in Iran to assess the perioperative mortality of children. Perioperative mortality is a vital tool for assessing the quality of care, safety of surgery and anesthesia provided to patients, especially in low-income and poor countries where access of patients to qualified surgical and anesthetic services is limited (7).

In the current study, 30-day perioperative mortality rate in a specialized pediatric hospital was 27.44 per 10000 procedures. In a study performed in Netherlands (6) on patients younger than 18 years old, hospital mortality within 30 -day post-surgery was 41.6 per 10000 procedures. According to a study in Melbourne, Australia (10), 30-day hospital mortality was 34.5 per 10000 procedures. Differences in mortality rates between different studies could be due to the variations in design and population of various studies (11).

Analysis of results showed that age of patients had a significant relationship with time interval between surgery and death, so that most number of deaths especially in infants and children lower than 3 years old, were happened within 30-day post-surgery. The study performed by Pignaton et al. (12), showed that children younger than 1-year-old were the major risk of perioperative mortality. In a five-year study to investigate the incidence and factors of perioperative cardiac arrest and mortality in a pediatric surgical population, the age of less than 1 year was identified as the main risk factor (13). According to the results, sex of patients was not a major predictor for perioperative mortality. In a multicenter, cohort study in low-income countries to measure 30-day postoperative mortality in children aged $<16$ years, sex of 
patients was not determined as a predictor of mortality (14). In contrast to the present study, a significant relationship between female sex and perioperative mortality was found in a study conducted in Ghana (15). In a study in California (16), individuals $<21$ years old who had cardiac surgery were selected to evaluate the role of gender in cardiovascular outcomes. Results showed that female sex was a risk factor for mortality among children who underwent cardiac surgery. This result became more interesting when it was clear that the proportion of neonates in females was less than males, and procedures that were used for females had lower risk compared with males.

In the present study, the mortality rate decreased significantly with age; so that the mortality rate in children over 10 years of age was 4.7-fold lower than in children less than 1 year of age. In a study of children under the age of 15 in Nigeria, the risk of death in children under the age of 1 was nine times higher than in older children (7). Rising risk in this age group can be related to congenital anomalies and sepsis (17). This may also be due to the immature status of immune systems in neonates and infants (18).

The present study did not show a significant relationship between postoperative mortality and emergency surgical status, which contradicts the results of studies conducted in developing low-income countries. Bharti et al. (13), and Bunchungmongkol et al. (19), expressed that patients whom surgery was at emergent status had more risk of perioperative mortality compared with cases of elective surgery.

In present research, type of surgery was determined as an indicator of perioperative mortality. In a study done at a Brazilian tertiary hospital (12) to evaluate the perioperative and anesthesia-related mortality rates, surgery-related factors were determined as one of two major causes of mortality. Moreover, in the Brazilian study (12), complications associated with cardiac surgery were among the most frequent causes of deaths. Cardiac disease was the most frequent associate disease among the cases of mortality according to the results of present research. According to Flick et al. (20), and Van der Griend et al. (10), cardiac surgery leads to higher rates of perioperative mortality compared with non-cardiac surgery.

\section{Conclusion}

The results showed a remarkable decrease in the number of perioperative mortality over time that may be due to better monitoring and patient care. Children lower than 1 year and type of surgery were the main indicators of perioperative mortality.

\section{Declarations}

Ethics approval and consent to participate: Ethics committee of Mashhad University ofMedical sciences approved the study. Written informed consent for participation in the study was obtained where participants are children (under 16 years old) from their parent or guardian.

Consent for publication: Not applicable 
Availability of data and material: The datasets used and/or analyzed during the current study are available from the corresponding author on reasonable request.

Competing interests: The authors declare that they have no competing interests.

Funding: funding had no role in the design of the study and collection, analysis, and interpretation of data and in writing the manuscript.

Authors' contributions: MG conceived and designed the study. MS participated in data collections and drafted the current manuscript, with critical review by MG. All authors contributed, read and approved the final manuscript.

\section{Acknowledgments}

We thank from Dr.sheikh hospital and its members who helped with this study.

\section{References}

1. Rabbani A, Kaviani A, Jalili D, Esmaeili Javid Gh R. Comparative evaluation of postoperative Mortality in Imam Khomeini hospital. Journal of school of public health institute of public health research. 2004;4(8):59-68.

2. Izadi N, Shetabi HR, Bakhtiari S, Janatalmakan M, Parabi M, Ahmadi K. The Rate and Causes of Infant Mortaliry in the Hospitals of Kermanshah Province During 2011-2014. J Rafsanjan Univ Med Sci. 2016;15(2):129-38.

3. Rasti R, Jahanpour F, Motamed $\mathrm{N}$. The effect of parental presence on anxiety during anesthesia induction in children 2 to 11 years of age undergoing surgery. J Jahrom Univ Med Sci. 2014;12(1):916.

4. Goodman LF, St-Louis E, Yousef Y, Cheung M, Ure B, Ozgediz D, Ameh EA, Bickler S, Poenaru D, Oldham K, Farmer D. The global initiative for children's surgery: optimal resources for improving care. Eur J Pediatr Surg. 2018 Feb;28(01):051-9.

5. Akbilgic O, Langham MR Jr, Walter Al, Jones TL, Huang EY, Davis RL. A novel risk classification system for 30-day mortality in children undergoing surgery. PloS one. 2018;13(1).

6. de Bruin L, Pasma W, van der Werff DBM, et al. perioperative hospital mortality at a tertiary paediatric institution. Br J Anaesth. 2015;115:608 - 15.

7. Talabi AO, Sowande OA, Adenekan AT, Adejuyigbe O, Adumah CC, Igwe AO. A 10-year retrospective review of perioperative mortality in pediatric general surgery at Ile-Ife Hospital, Nigeria. Journal of pediatric surgery. 2018 Oct 1;53(10):2072-6.

8. Newton MW, Hurt SE, McEvoy MD, Shi Y, Shotwell MS, Kamau J, Nabulindo S, Ngumi ZW, Sandberg WS, Sileshi B. Pediatric Perioperative Mortality in KenyaA Prospective Cohort Study from 24 Hospitals. Anesthesiology: The Journal of the American Society of Anesthesiologists. 2020 Mar 1;132(3):452 - 60 . 
9. Gonzales LP, Pignaton W, Kusanp PS, et al. Anesthesia-related mortality in pediatric patients: a systematic review. Clinics. 2012;67:381 - 7.

10. van der Griend BF, Lister NA, McKenzie IM, et al. Postoperative mortality in children after 101885 anesthetics at a tertiary pediatric hospital. Anesth Analg. 2011;112:1440-7.

11. Deshpande JK. Cause and effect or conjecture? A call for consensus on defining "anesthesia-related mortality". Anesthesia \& Analgesia. 2011 Jun 1;112(6):1259-61.

12. Pignaton W, Braz JR, Kusano PS, Módolo MP, De Carvalho LR, Braz MG, Braz LG. Perioperative and anesthesia-related mortality: an 8-year observational survey from a tertiary teaching hospital. Medicine. 2016 Jan;95(2).

13. Bharti N, Batra YK, Kaur H. Paediatric perioperative cardiac arrest and its mortality: database of a 60month period from a tertiary care paediatric centre. European Journal of Anaesthesiology (EJA). 2009 Jun 1;26(6):490-5.

14. Collaborative G. Determinants of morbidity and mortality following emergency abdominal surgery in children in low-income and middle-income countries. BMJ global health. 2016 Dec 1;1(4):e000091.

15. Peiffer S, FGCSb RY, Ofosu-Akromah M, Arkorful TE, Agyemang E, Tsai A, Oh J. Predictors of Poor Postoperative Outcomes in Pediatric Surgery Patients in Rural Sub-Saharan Africa.

16. Chang RK, Chen AY, Klitzner TS. Female sex as a risk factor for in-hospital mortality among children undergoing cardiac surgery. Circulation. 2002 Sep;17(12):1514-22. 106(.

17. Livingston MH, DCruz J, Pemberton J, Ozgediz D, Poenaru D. Mortality of pediatric surgical conditions in low and middle income countries in Africa. Journal of pediatric surgery. 2015 May 1;50(5):760-4.

18. Upperman J, Ford H. Sepsis and Related Considerations. In: Grosfeld J, O’Neil J, Fonkalsrud E, Coran A, editors. Pediatric Surgery. 6th ed. Philadelphia: Mosby Elsevier; 2006. pp. 156-77.

19. Bunchungmongkol N, Punjasawadwong Y, Chumpathong S, Somboonviboon W, Suraseranivongse S, Vasinanukorn M, Srisawasdi S, Thienthong S, Pranootnarabhal T. Anesthesia-related cardiac arrest in children: the Thai Anesthesia Incidents Study (THAI Study). Medical journal of the Medical Association of Thailand. 2009 Apr 1;92(4):523.

20. Flick RP, Sprung J, Harrison TE, et al. Perioperative cardiac arrests in children between 1988 and 2005 at a tertiary referral center: a study of 92,881 patients. Anesthesiology. 2007;106:226-37. 